\title{
Ice dolines on Larsen Ice Shelf, Antarctica
}

\author{
Robert Bindschadler, ${ }^{1}$ Ted A. Saambos,${ }^{2}$ Helmut Rott,${ }^{3}$ Pedro Skvarga, ${ }^{4}$ Patriaia Vornberger ${ }^{5}$ \\ ${ }^{1}$ Oceans and Ice Branch, NASA Goddard Space Flight Center, Code 971, Greenbelt, MD 20771, U.S.A. \\ ${ }^{2}$ National Snow and Ice Data Center, University of Colorado, Boulder, CO 80309-0449, U.S.A. \\ ${ }^{3}$ Institut für Meteorologie und Geophysik, Universität Innsbruck, A-6020 Innsbruck, Austria \\ ${ }^{4}$ Instituto Antártico Argentino, Cerrito 1248, C1010AAZ Buenos Aires, Argentina \\ ${ }^{5}$ General Sciences Corporation, SAIC, Beltsville, MD 20705-2675, U.S.A.
}

\begin{abstract}
Ice dolines on the Larsen Ice Shelf, Antarctica, are observed to be elongated depressions a few hundred meters across and up to $19 \mathrm{~m}$ deep. One-meter resolution imagery is used to quantify these dimensions. Elevation profiles across five dolines are derived by photoclinometry. Landsat and radar imagery is also used to show that dolines can form in a single melt season and persist for years. Dolines occur in clusters and in direct proximity to surface meltwater lakes. Field observations suggest dolines form by collapse into a subsurface cavity. A direct hydraulic connection with the underlying ocean is believed necessary to drain water that would otherwise collect in dolines. A formation hypothesis is discussed consistent with these observations and with energyand hydrostatic-imbalance considerations.
\end{abstract}

\section{INTRODUGTION}

Doline is a geologic term describing a rounded hollow that can range in width from 1 to $100 \mathrm{~m}$ and in depth from ten to hundreds of meters (AGI, 1976). Mellor (1960) was the first to suggest the term ice doline be applied to depression features seen on ice. Their size, hundreds of meters across, is the principal characteristic distinguishing them from potholes (Sturm, 1987), which are smaller and associated primarily with surging glaciers, and ice calderas (Stephenson and Fleming, 1940), which are larger. Ice blisters are also smaller and elevated above the mean regional surface (Kovacs, 1992). Moore (1993) summarizes earlier observations of ice dolines and reviews ideas of formation mechanisms. Almost all observations of ice dolines are on ice shelves, and all are in areas of meltwater ponds. Sparked by the detail visible in a recent IKONOS $1 \mathrm{~m}$ resolution image, we have gathered a variety of remote-sensing data of these features and, along with direct field observations, discuss their characteristics and revise and extend hypotheses on their formation and evolution.

\section{DATA}

An IKONOS image was collected on 5 October 2000 near the front of the Larsen Ice Shelf, Antarctica (Fig. 1). The sensor records reflected solar radiation in four narrow visible and near-infrared spectral bands at $4 \mathrm{~m}$ spatial resolution and in one wide panchromatic band at $1 \mathrm{~m}$ spatial resolution. At-satellite reflectance in each band is digitized to 11 bits over a wide dynamic range. The high spatial and radiometric resolution enabled a detailed rendering of the subtle topographic relief of the ice-shelf surface prior to the onset of summer melting and included a set of ice dolines (Fig. 2). We number these dolines (1-13) to facilitate our discussion.

Other satellite imagery assisted our analysis. The earliest image (a 20 February 1979 Landsat image used by Swithinbank, 1988, p. B105) is not available in digital form. Four other Landsat images were collected on 1 March 1986, 19 January 1988, 6 February 1989 and 21 February 2000. All of these images are at $30 \mathrm{~m}$ spatial resolution with the addition of a $15 \mathrm{~m}$ spatial resolution panchromatic band for the most recent image (Fig. 3).

Radar sensors penetrate clouds, allowing more routine and reliable monitoring of persistently cloud-covered areas. From 1995 to 1999, a series of seven European Remotesensing Satellite (ERS-1/-2) synthetic aperture radar (SAR) images of the ice-dolines area were available. These sensors measure radar backscatter of the surface at a spatial resolution of $25 \mathrm{~m}$. Backscatter imagery differs markedly from visible reflectance imagery. Nevertheless, ice dolines were identified due to sensitivity of backscatter to the presence of water and the unique shapes of surface meltwater basins.

Field research motivated by other glaciological interests has resulted in several ancillary observations of the Larsen Ice Shelf dolines. These include some photographs of ice dolines (Fig. 4) and a few ground surveys across these features. In addition, a joint British Antarctic Survey (BAS)-Instituto Antártico Argentino (IAA) airborne radioecho sounding survey carried out in early 1998 provided local ice thickness (personal communication from H. Corr, 2001).

\section{DESGRIPTION OF ICE DOLINES}

The ice dolines observed on the northern Larsen Ice Shelf are elongated depressions with horizontal dimensions ranging from $1000 \mathrm{~m} \times 500 \mathrm{~m}$ (the largest doline in Figure 3) to $<100 \mathrm{~m}$ in either dimension. Vertical dimensions are discussed later, but the shading in Figure 2 shows that their depth is much larger than the topographic relief on the rest of the ice shelf. Orientations of the long axes exhibit a 


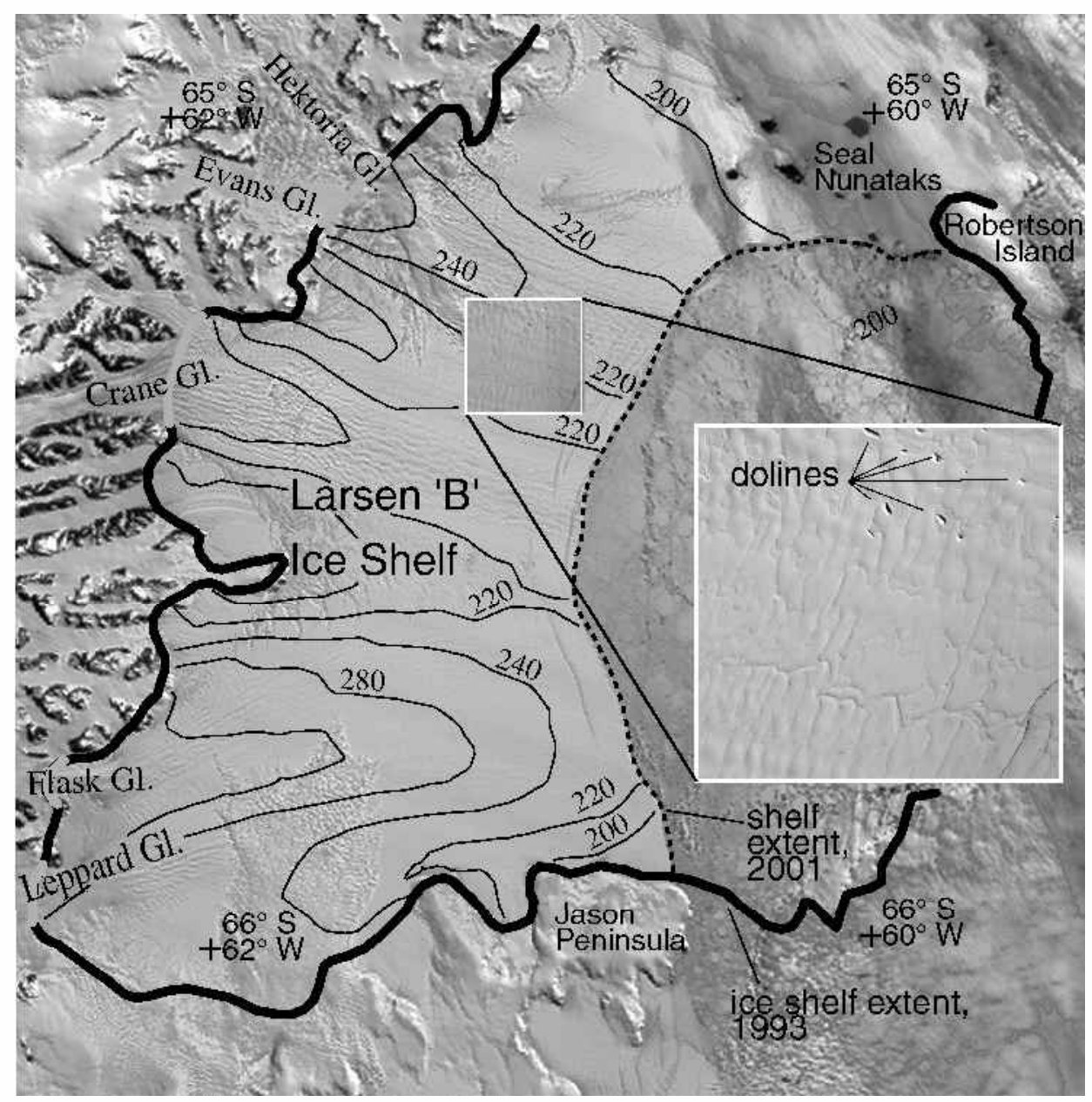

Fig. 1. Overview of Larsen B Ice Shelf using a moderate-resolution imaging spectroradiometer (MODIS) channel 1 image at $250 \mathrm{~m}$ resolution collected on 19 November 2000. Thick line is 1993 boundary of ice shelf. Thin lines are contours of ice thickness (from Scambos and others, 2000). IKONOS image superimposed at correct location and enlarged on right.

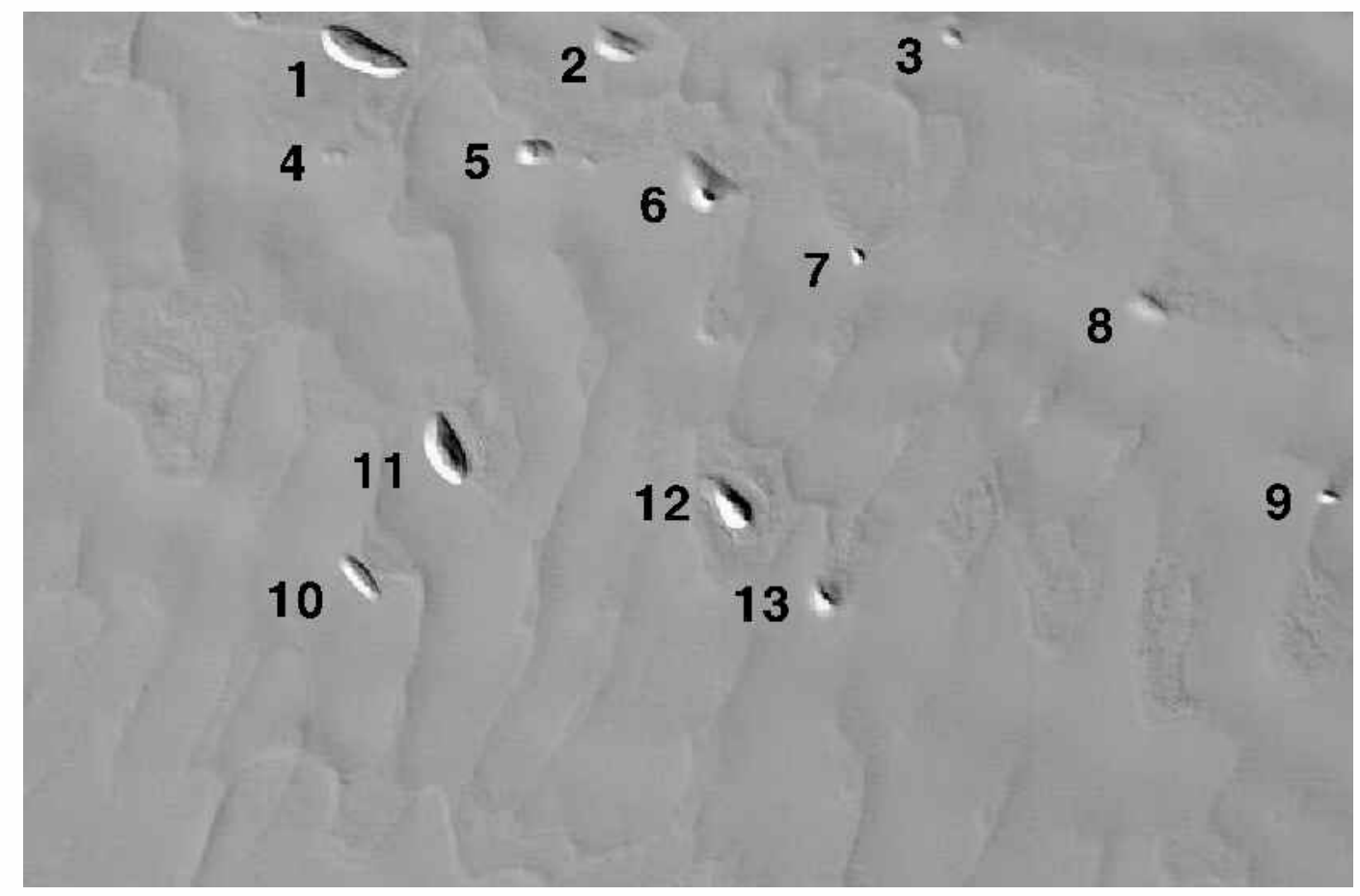

Fig. 2. Portion of panchromatic band of IKONOS image $(9.25 \mathrm{~km} \times 6.1 \mathrm{~km})$ collected on 5 October 2000. Dolines are numbered for discussion in text. Orientation is north-up and solar illumination is from upper right. 


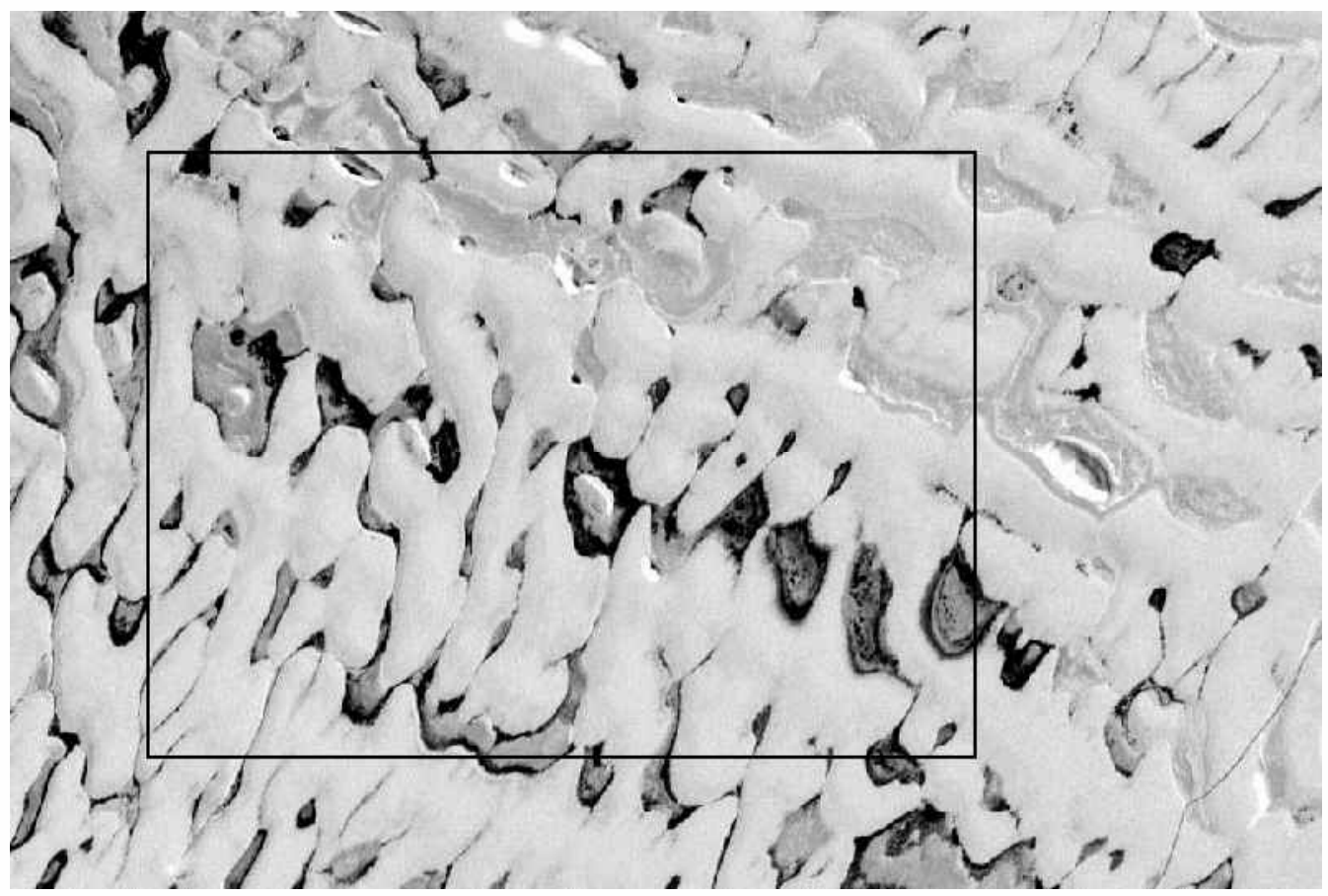

Fig. 3. Portion of panchromatic band of Landsat 7 image $(15 \mathrm{~km} \times 10 \mathrm{~km})$ collected on 21 February 2000. Outline indicates location of Figure 2. Orientation is north-up and solar illumination is from upper right.

general preferred direction roughly parallel to the ice flow. In Figure 2, dolines 1-8, near the top (north) of the image, are aligned more closely with the flow direction than the set of four southernmost dolines (10-13).

The Larsen dolines occur primarily in clusters of limited spatial extent, although a few isolated dolines are also observed. On Larsen Ice Shelf in 1979, Swithinbank (1988) observed five dolines north of Seal Nunataks arranged around a larger central depression. This cluster spans an area about $4 \mathrm{~km}$ across. Farther to the south, the 13 dolines in the IKONOS image form a cluster about $4 \mathrm{~km} \times 7 \mathrm{~km}$. A few of these (Nos. 3, 4 and 8) appear more subtle, suggesting

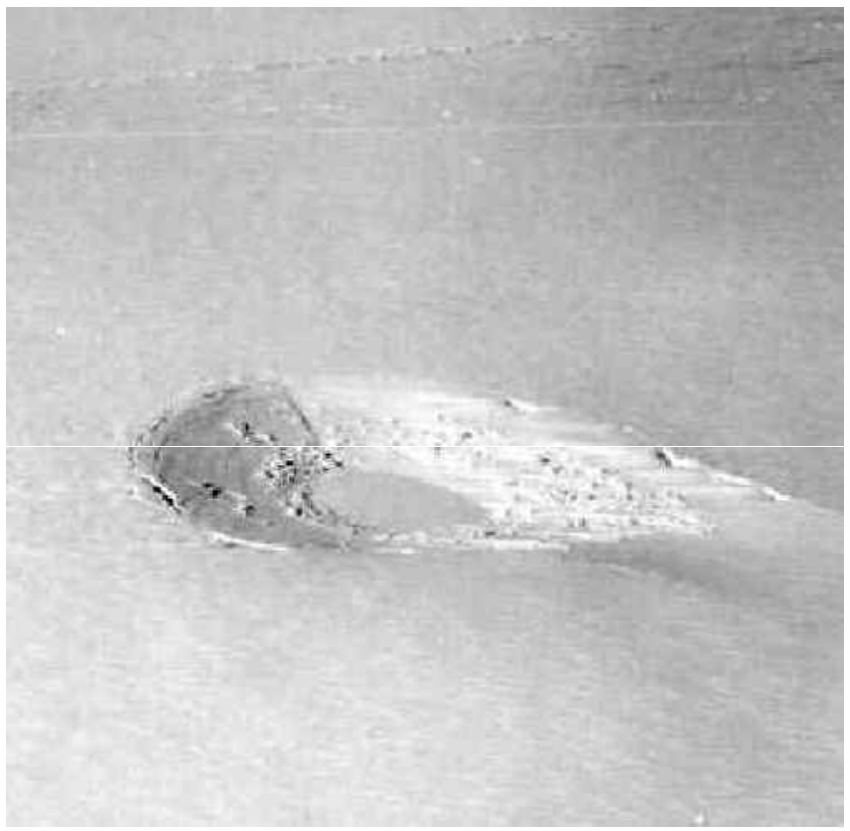

Fig. 4. Aerial photograph of doline on Larsen Ice Shelf taken on 25 February 1999. they are either older features or less well-developed depressions. Examination of the 5 year series of SAR images confirms that some of the dolines in Figure 2 have persisted for many years. Doline No. 6 is recognizable as far back as a 1986 Landsat image.

Ice dolines can form quickly. Comparison of the IKONOS image with the Landsat image collected the previous summer (Fig. 3) demonstrates that the very elongated doline No. 10 at the margin of a lake was created sometime during the 8 months between these images. Further north, the cluster observed by Swithinbank (1988) on the 1979 image is absent in a 1975 Soyuzkarta image (Skvarca, 1993).

The northernmost sections of the Larsen Ice Shelf, in which the dolines occur, have recently disintegrated or significantly retreated (Rott and others, 1996; Skvarca and others, 1999). However, the literature contains numerous observations of dolines in regions of ice shelves that appear to be stable (e.g. Amery, George VI and Lazarev ice shelves (Swithinbank, 1988; Moore, 1993)). The features vary in lateral scale, and especially in vertical height (up to $80 \mathrm{~m}$ deep in the Amery), but are invariably located near melt-pond features.

The Larsen doline clusters bear no consistent relation to either thicker glacier-fed flows extending along the ice shelf or thinner areas between these flows (Fig. 1). However, field observations suggest they occur in "weak" areas of the ice shelf. The dolines in Figure 2 occur in ice fed into the ice shelf by Evans Glacier (Fig. 1). Based on the modern velocity field, the ice containing the dolines in the IKONOS image entered the ice shelf about 180 years ago and is presently about $220 \mathrm{~m}$ thick (Scambos and others, 2000).

The IKONOS and Landsat 7 images confirm that the Larsen dolines occur within or immediately adjacent to the boundaries of surface meltwater ponds or lakes. Lake boundaries, seen in the late austral summer Landsat image of 21 February 2000 (Fig. 3), are detectable as faint edges in the IKONOS image the following austral spring (Fig. 2). There seems to be only one relict shoreline for each lake, 



Fig. 5. Doline No.11 ( see Fig. 2). ( a) IKONOS panchromatic image $(1050 \mathrm{~m} \times 700 \mathrm{~m})$ with transect position indicated by solid line (aligned with Sun). (b) Profile of brightness values (DN) across profile from lower left to upper right. (c) Relative elevation profile derived by photoclinometry as discussed in text. 
suggesting both that this is the maximum lake extent and that the lakes do not sustain a lower stage after this maximum stage is reached.

The extensive system of meltwater lakes forms in early to mid-austral summer during warm years (Scambos and others, 2000). These lake systems are revealed by the Landsat 7 image to be interconnected strings of melt ponds, aligned parallel to the flow and separated by flow-band ridges. Cross-cutting surface cracks or troughs also appear to be water-filled, and thus are part of the water system. In some regions, the lakes are drained by sharp, newer cracks or, apparently, by dolines.

The largest dolines, both on the Larsen and on other shelves, have flat floors (Fig. 4), and most contain a longitudinal crack along their center line. We believe the doline photographed in Figure 4 corresponds to the large doline No. 11 in Figure 2. Figure 5 shows more detail of doline No. 11. Surface crevasses at the edge of a doline parallel to the edge are seen in many dolines. Field observations of dolines suggest these crevasses and associated disruptions of the surface are caused by collapse of surface layers into a subsurface cavity.

\section{DEPTH OF IGE DOLINES}

The spatial and radiometric detail of the IKONOS image permits quantification of the topographic shape of dolines. Photoclinometry converts image brightnesses to Sun-parallel slopes that are then integrated to obtain elevation profiles (Bindschadler and Vornberger, 1994). The critical assumption is that the surface behaves as a Lambertian reflector of constant reflectance so that the image brightness is directly related to the geometry of the surface topography. The governing equation is:

$$
\mathrm{DN}=C \int_{\lambda} T(\lambda)\left[I(\lambda) R \cos \theta-L_{0}(\lambda)+S(\lambda)\right] \mathrm{d} \lambda,
$$

where DN is the image brightness in sensor units, $I$ is the exoatmospheric solar radiance, $C$ is the conversion from radiance to sensor units, $R$ is the surface reflectance, $\theta$ is the angle between the Sun and the surface normal, $L_{0}$ is the radiance (usually negative) at $\mathrm{DN}=0, S$ is the path radiance, $T$ is the bandpass transmittance and the integration is taken over the wavelength range, $\lambda$, of the sensor.

For our application, we reduce Equation (1) to

$$
\mathrm{DN}=C I_{\mathrm{f}} R \cos \theta+B
$$

where $I_{\mathrm{f}}$ represents the filtered exoatmospheric radiance and $B$ collects the terms for radiance offset and path radiance. When a range of surface slopes is known within the image, $C$ and $B$ can be determined empirically (Scambos and Fahnestock, 1998), but this is not the case here. Instead, we determine $B$ by finding the darkest pixel within the image $(\mathrm{DN}=119)$. It occurs at the edge of a crevasse. Assuming this pixel is entirely within shadow, we set $\cos \theta=0$ and calculate $B=119$. $C$ is determined using the mean surface slope throughout the scene and the mean DN of the scene. Altimetry of the shelf surface (Bamber and Bindschadler, 1997) indicates that the mean shelf surface is nearly horizontal, and we assume that this surrounding surface has zero mean slope. The mean DN is 1014 and this corresponds to $\theta$ equal to the solar zenith angle of $65.54^{\circ}$

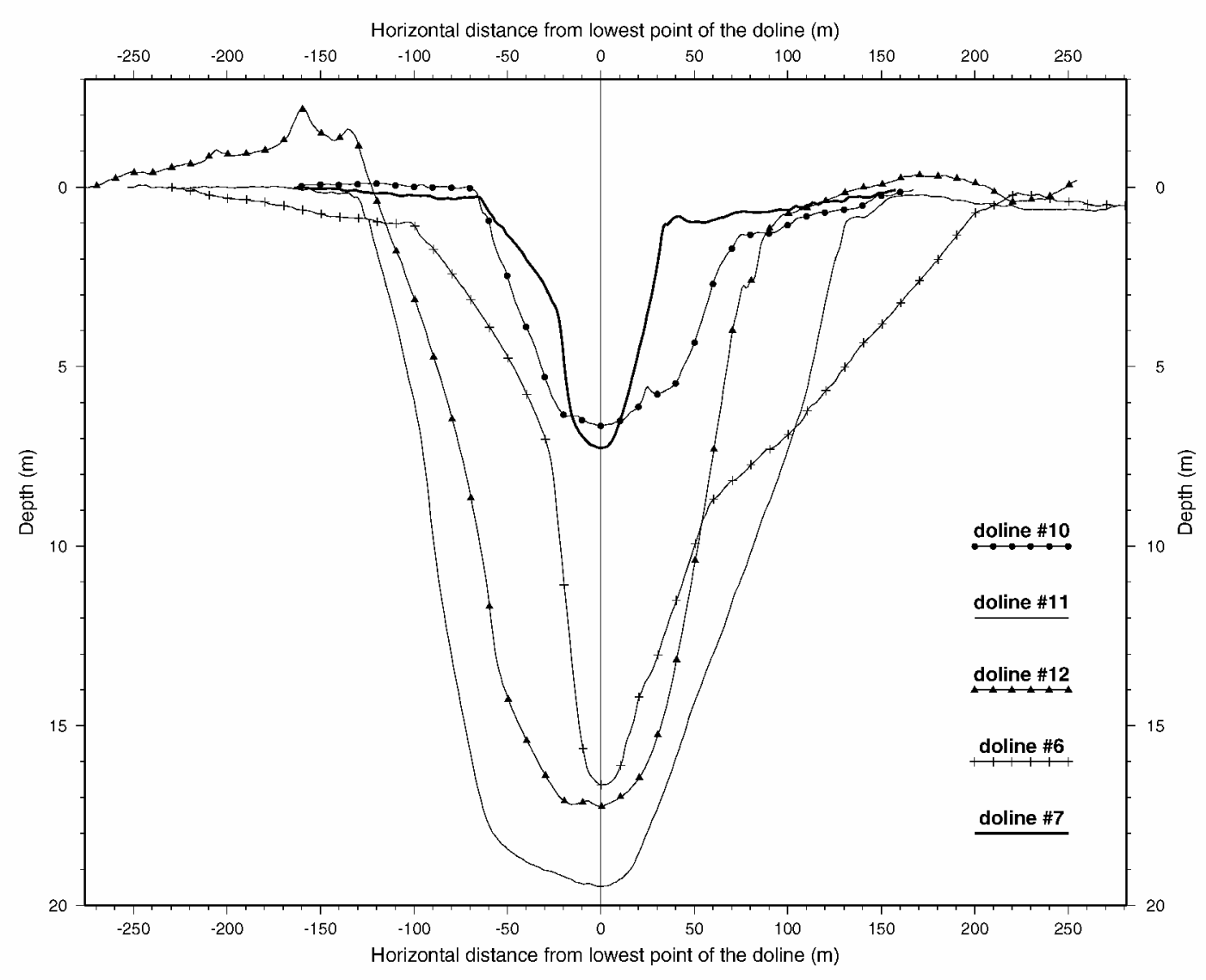

Fig. 6. Relative elevation profiles for five dolines (Nos. 6, 7, 10, 11, 12; see Fig. 2). Profile positions are adjusted horizontally to match the deepest location of each profile, and vertically to match the initial elevation of each profile. 
( $\cos \theta=0.4141)$. Substituting these values into Equation (2) results in

$$
\cos \theta=4.63 \times 10^{-4}(\mathrm{DN}-119),
$$

which can be used to determine the along-transect slope for each pixel. Assuming $R$ and $I_{\mathrm{f}}$ are constant throughout the scene makes Equation (3) independent of these parameters.

Assuming a flat ice-shelf surface adds the further constraint that the elevation should be the same at each end of a profile across a doline. The average increase in DN along the Sun-facing slopes was very close to the average decrease in DN along the slope tilted away from the Sun. Because the cosine is not a linear function, the Sun-facing slopes consistently produced a larger elevation difference than the slopes on the opposite sides of the dolines. The difference was typically $2 \mathrm{~m}$. To account for this, the $\cos \theta$ term in Equation (3) was replaced by $\cos \theta_{\mathrm{m}}-\left(\theta-\theta_{\mathrm{m}}\right) \sin \theta_{\mathrm{m}}$, where $\theta_{\mathrm{m}}$ corresponds to a horizontal surface. The substitution of this linear expression produced elevation profiles that satisfied the constraint of equal elevation at each end. This modification of Equation (3) represents a deviation from the assumption of Lambertian reflectance.

Figure 5 illustrates the photoclinometric method for doline No. 11. The DN profile shows high variability. Most of this variation is believed to be signal (note the large blocks evident on the inside slopes of the doline in Figure 4). The resultant elevation profile is rather smooth, with the Sun-facing slope a nearly constant $14^{\circ}$, the opposite slope a nearly constant $12^{\circ}$ and a $70 \mathrm{~m}$ wide base that is nearly flat. Depth uncertainty is estimated to be $<10 \%$. The main error sources are the deviation from Lambertian reflectance and the geometry of the darkest pixel, both discussed above.

Figure 6 shows five doline profiles. The widths and depths are summarized in Table 1 . This limited sampling suggests two groups. The wider dolines $(6,11$ and 12$)$ have floors very near sea level. Ice thickness is approximately $220 \mathrm{~m}$. With a small adjustment for dense firn, we expect sea level to be slightly more than $22 \mathrm{~m}$ below the surface. The narrower pair (Nos. 7 and 10) reach a depth of only $7 \mathrm{~m}$, but the width/depth ratio of all the dolines is nearly constant. It may be relevant to recall that doline No. 6 has persisted for $>10$ years, while doline No. 10 is no older than 8 months.

Even the deepest doline (No. 11, Table 1) has its floor a few meters above estimated sea level. Upon opening of a pathway through the ice shelf, the doline-forming lakes would drain until the lake surface is in hydrostatic equilibrium with the ocean. Since the column of draining water is fresh, this level would be higher than sea level, because of the lower density of the fresh-water column. Given a column of $200 \mathrm{~m}$, the height difference is $5.5 \mathrm{~m}$ between columns of sea water and fresh water with densities of 1.028 and $1 \mathrm{~kg} \mathrm{~m}^{-3}$,

Table 1. Dimensions of dolines ( see Fig. 2 for doline identification)

\begin{tabular}{lrrrrr}
\hline & \multicolumn{5}{c}{ Doline No. } \\
& 6 & 7 & 10 & 11 & 12 \\
\hline Width (m) & 300 & 100 & 140 & 260 & 230 \\
Depth (m) & 17 & 7 & 7 & 19 & 17 \\
Width/depth & 17.6 & 14.3 & 20 & 13.7 & 13.5 \\
& & & & & \\
\hline
\end{tabular}

respectively. Thus, dolines 6,11 and 12 may all represent cases where the floor's elevation is at sea level.

\section{FORMATION OF ICE DOLINES}

Moore (1993) discusses previous thoughts on formation of ice dolines. We extend some of these ideas and suggest some new possibilities based on our observations. Their occurrence within or adjacent to surface meltwater lakes strongly suggests that water is directly involved. Many dolines are visible as dry basins in the middle of summer, when meltwater lakes are prevalent (see Fig. 3). This suggests they maintain a hydraulic connection with the underlying sea. That their depths never exceed the depth to sea level further supports a connection. Large blocks on the sloping sides of dolines, and crevasses at the edge of the dolines both suggest that dolines form by collapse into a subsurface void.

It is possible that internal cavities are created upstream either within the feeding glaciers or when the glaciers enter the ice shelf. This would help explain the preferred orientation of doline clusters, but large cavities would tend to close over time through creep. They also would create a hydrostatic imbalance that would either raise the ice shelf underneath the cavity or require a much thinner ice thickness to prevent the raising of the surface. Neither large voids nor frequent regions of much thinner ice-shelf ice have been reported despite extensive radio soundings.

We pursue the line of reasoning that melting creates the voids, and begin by considering the energy required to remove the void space of a doline. Using typical values of 300, 200 and $20 \mathrm{~m}$ for the doline's length, width and depth, respectively, a characteristic doline volume is $600000 \mathrm{~m}^{3}$. Assuming a relatively high density of $700 \mathrm{~kg} \mathrm{~m}^{-3}$ for the material removed in the doline, justified by the frequent saturation of this firn, the amount of heat required to melt this volume of ice is $1.5 \times 10^{14} \mathrm{~kg} \mathrm{~m}^{2} \mathrm{~s}^{-2}$

Lake drainage releases potential energy, but this is orders of magnitude too small to contribute significantly to doline formation. A $5 \mathrm{~m}$ deep lake $1 \mathrm{~km}^{2}$ in area draining $20 \mathrm{~m}$ into the firn releases only $10^{8} \mathrm{~kg} \mathrm{~m}^{2} \mathrm{~s}^{-2}$ of energy.

The largest source of energy is solar radiation. Lowalbedo lakes are effective absorbers of solar radiation and provide efficient storage. Fetterer and Untersteiner (1998) discuss the similar situation of melt ponds on sea ice. They point out that a melt pond's energy-absorbing efficiency is achieved because water warmed a few degrees above an initial temperature of $0^{\circ} \mathrm{C}$ becomes denser than underlying layers and sinks. Convection is set up due to the density gradient transferring most of the heat to the base of the lake, leaving less to be radiated back to the atmosphere. Clouds may block the direct illumination of the surface, but they diffuse the light. In situations of low solar illumination and thin clouds, the surface incident energy can actually increase (personal communication from R. Cahalan, 2001). Across the visible spectrum, the Sun provides approximately $1300 \mathrm{~W} \mathrm{~m}^{-2}$ of energy. Assuming an average solar zenith angle of $70^{\circ}$ during the summer and $90 \%$ absorption by the water, a $1 \mathrm{~km}^{2}$ lake will absorb $34.6 \times 10^{12} \mathrm{~kg} \mathrm{~m}^{2} \mathrm{~s}^{-2} \mathrm{~d}^{-1}$ and retain enough energy in just a few days to melt the doline. This simple calculation contains many assumptions, but shows that the Sun provides sufficient energy to melt dolines and that lakes can effectively receive and store this energy.

We hypothesize that a void is created within the ice shelf 
when a lake drains into the ice shelf through a crack in the impermeable layer underneath a lake. The melting is accomplished by the release of both sensible and latent heat of the lake water. The stress caused by the distribution of normal stresses created by a network of large surface meltwater lakes may be one means to form this crack. Figure $7 \mathrm{a}$ illustrates how this summer situation causes tensile stresses between lakes. If the lakes cover more than half the surface, the area experiencing tensile stresses will extend beneath the lake margins. If a crack is formed here, the lake water will begin to drain through it. The volume of water will maintain an adequate pressure head forcing the crack to stay open and to deepen as discussed by Weertman (1973).

Field observations indicate that Larsen Ice Shelf is composed of very dense firn, but observations do not extend beneath the lakes. It is possible that the firn between lakes is denser than beneath the lakes. Once an impermeable layer is formed - and surface lakes are undoubtedly underlain by such layers - the firn beneath is less subject to rapid densification. Less dense firn would also be expected if the warm summers were a recent climatic trend.

Whatever density of material is encountered by the draining lake water, it will be colder than the water. Both the sensible and latent heat of the water will contribute to warming and melting the firn (Fig. 7b). Conversion of firn to water reduces volume and creates void space. The amount of melting and the original firn density will determine the size of the cavity.

As melting proceeds, Weertman's mechanism for down-

(a)
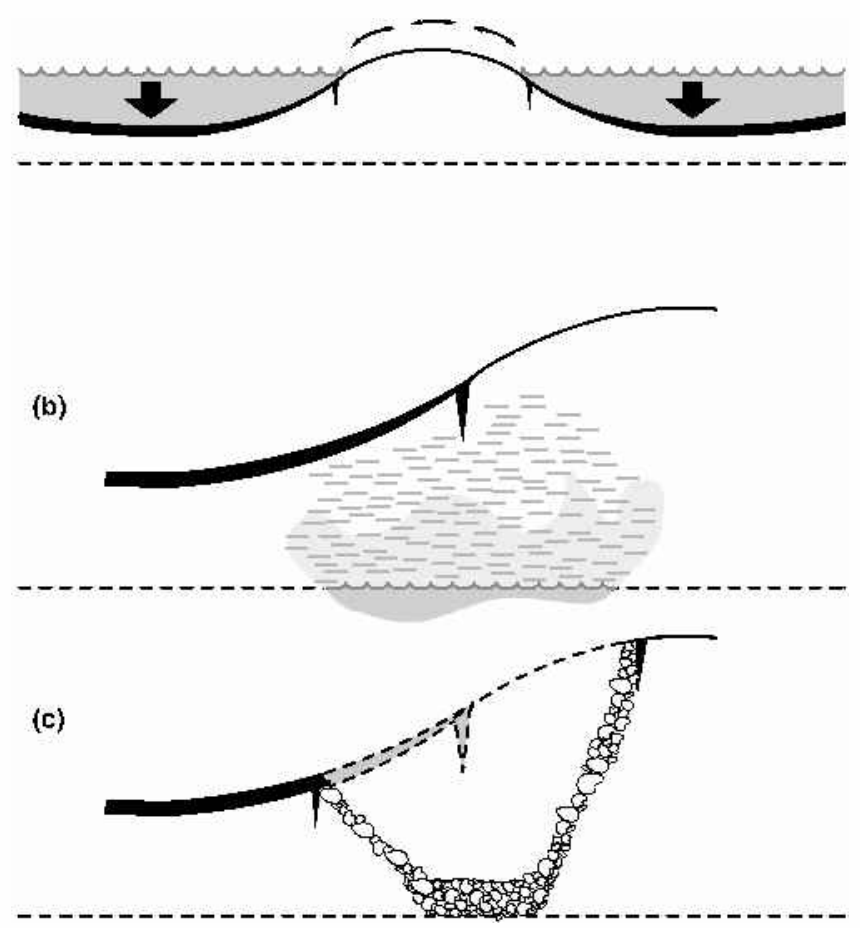

Fig. 7. Schematic diagram of possible doline formation. (a) Unequilibrated loading of summer surface due to meltwater collection in lakes creates tensile stresses. Tensile cracks at the lake edge allow water to drain through the thicker impermeable crust underlying lakes. (b) Draining water melts void in subsurface firn. Dashed line represents sea level. If excess meltwater connects with sea water, the two levels equilibrate. (c) Increasing void eventually leads to collapse of ceiling, creating doline. ward propagation of water-filled crevasses will continue to apply. If the water supply is maintained within the growing cavity, the initial crevasse, and any others that may form, should propagate through the entire ice shelf. This will allow the drainage of the water within the cavity to the underlying ocean. For cavities large enough that their base is below sea level, water will only drain to sea level, or slightly higher because of the difference in density of fresh water and sea water, as mentioned earlier.

Once voids are sufficiently large, the ceiling collapses, forming a doline (Fig. 7c). If the cavity contains residual water, the collapsing ice will float in this residual pool, creating the flat doline floors observed for the larger dolines. Drifting snow smooths the roughened sides of the doline.

\section{EVOLUTION OF ICE DOLINES}

Our observations confirm that dolines persist over many years without undergoing major changes. Melting in subsequent years seems to keep pace with the collection of drifting snow. There is no indication that excess meltwater fills up these basins. Figure 3 shows that the areas around dolines are well drained, even when large meltwater lakes are prevalent elsewhere. Thus, dolines probably retain their drainage connection to the ocean.

There must be also a buoyancy force causing the ice underneath the doline to creep upward to re-establish hydrostatic equilibrium. The distribution of this force will cause the doline shape to change with time. Assuming a simplified cylindrical geometry where $\rho_{\text {ice }}$ is the density of ice, $g$ is the gravitational acceleration, $r$ is the radius of the doline and $d$ is the depth of the doline, the buoyancy force underneath the doline is:

$$
F=\rho_{\text {ice }} g \pi r^{2} d .
$$

The doline depth, $d$, is not necessarily related to sea level in this general case. This force is distributed along the cylindrical surface of area

$$
A=2 \pi r(H-d),
$$

where $H$ is the hydrostatically supported ice thickness. The resulting shear stress is:

$$
\tau=\frac{F}{A}=0.5 \rho_{\text {ice }} g r \frac{d}{H-d} .
$$

If the floor of the doline is at sea level, then

$$
\rho_{\text {ice }} H=\rho_{\text {water }}(H-d)
$$

and

$$
\tau=\frac{\left(\rho_{\text {water }}-\rho_{\text {ice }}\right) g r}{2} \approx \frac{\rho_{\text {water }} g r}{20} .
$$

In the plastic limit, $\tau$ equals 1 bar and implies a maximum doline radius of approximately $200 \mathrm{~m}$. This agrees roughly with the observed size of dolines.

Removing the restriction that the floor of the doline is at sea level allows examination of how the profile of the doline may evolve as the buoyancy force is distributed underneath the doline. Equation (6) expresses a linear increase of $\tau$ with radius. This linear stress distribution is analogous to the laminar approximation of glacier flow where the horizontal shear stress varies linearly with depth. Again applying the plastic limit, the result is a parabolic profile of height that is tangent to the surface around the outer edge of the doline but steepens toward the center. Of the five dolines in Figure 6, only No. 6 has a profile that even vaguely resembles this 
convex-up shape. This suggests that yearly meltwater production and solar absorption reshape the dolines annually to a more bowl-like shape. During the summer periods when the doline is filled with water, the hydrostatic forces will be reversed and the vertical shear stresses will act to deepen the doline.

\section{SUMMARY}

Ice dolines on the Larsen Ice Shelf are observed to be elongated depressions occurring in isolated clusters in the region where extensive meltwater has been produced in recent years. Their dimensions are a few hundred meters across and up to $19 \mathrm{~m}$ deep. The record of satellite imagery shows that while some dolines persist for many years, a $7 \mathrm{~m}$ deep doline formed in no more than 8 months.

The positions of dolines, surrounded by or adjacent to large meltwater lakes, suggest that water is involved in their formation. Field observations of crevasses at their boundaries and of large ice blocks on their flanks suggest that dolines may form by collapse of a surface layer into an underlying void. Surface lakes absorb enough heat to melt the necessary doline volume. Unequilibrated normal stresses may provide a means to open cracks in the impermeable layers beneath the surface lakes, permitting drainage into the underlying material. Melting of the underlying firn and subsequent drainage of the meltwater to the ocean below could create cavities leading to ceiling collapse and doline formation.

A drainage connection also appears to persist as the region around dolines is more completely drained in summer than nearby areas. The characteristic size and transverse shape of dolines is explained by the mechanical response to the vertical stress distribution within the ice shelf.

\section{ACKNOWLEDGEMENTS}

We wish to thank NASA's Landsat Science Project Office for providing the IKONOS image that prompted this study. Other image data were supplied by NASA and the European Space Agency. H. Corr provided ice-thickness data from the 1998 joint BAS-IAA airborne sounding campaign. R. Thomas and C. Hulbe made useful comments. We also thank N. Young, I. Goodwin and J. Moore for their reviews of an earlier draft.

\section{REFERENGES}

American Geological Institute. 1976. Dictionary of geological terms. Alexandria, VA, Anchor Press. American Geological Institute.

Bamber, J. L. and R. A. Bindschadler. 1997. An improved elevation dataset for climate and ice-sheet modelling: validation with satellite imagery. Ann. Glaciol., 25, 439-444.

Bindschadler, R. A. and P. L. Vornberger. 1994. Detailed elevation map of Ice Stream C, Antarctica, using satellite imagery and airborne radar. Ann. Glaciol., 20, 327-335.

Fetterer, F. and N. Untersteiner. 1998. Observations of melt ponds on Arctic sea ice. 7. Geophys. Res., $103(\mathrm{Cl1})$, 24,821-24,835.

Kovacs, A. 1992. Correspondence. Ice-blister observations on glaciers, sea ice and rivers. F. Glaciol., 38(129), 314-316.

Mellor, M. 1960. Correspondence: Antarctic ice terminology: ice dolines. Polar Rec., 10(64), 92

Moore, J. 1993. Correspondence. Ice blisters and ice dolines. F. Glaciol., 39(133), 714-716.

Rott, H., P. Skvarca and T. Nagler. 1996. Rapid collapse of northern Larsen Ice Shelf, Antarctica. Science, 271(5250), 788-792.

Scambos, T. A. and M. A. Fahnestock. 1998. Improving digital elevation models over ice sheets using AVHRR-based photoclinometry. F. Glaciol., 44(146), 97-103.

Scambos, T. A., C. Hulbe, M. Fahnestock and J. Bohlander. 2000. The link between climate warming and break-up of ice shelves in the Antarctic Peninsula. 7. Glaciol., 46(154), 516-530.

Skvarca, P. 1993. Fast recession of the northern Larsen Ice Shelf monitored by space images. Ann. Glaciol., 17, 317-321.

Skvarca, P., W. Rack, H. Rott and T. Ibarzábal y Donángelo. 1999. Climatic trend and the retreat and disintegration of ice shelves on the Antarctic Peninsula: an overview. Polar Res., 18(2), 151-157.

Stephenson, A. and W. L. S. Fleming. 1940. King George the Sixth Sound. Geogr. 7., 96(3), 153-166.

Sturm, M. 1987. Observations on the distribution and characteristics of potholes on surging glaciers. 7. Geophys. Res., 92(B9), 9015-9022.

Swithinbank, C. 1988. Antarctica. U.S. Geol. Surv. Prof. Pap. 1386-B, B1-B138.

Weertman, J. 1973. Can a water-filled crevasse reach the bottom surface of a glacier? International Association of Scientific Hydrology Publication 95 (Symposium at Cambridge 1969-Hydrology of Glaciers), 139-145. 